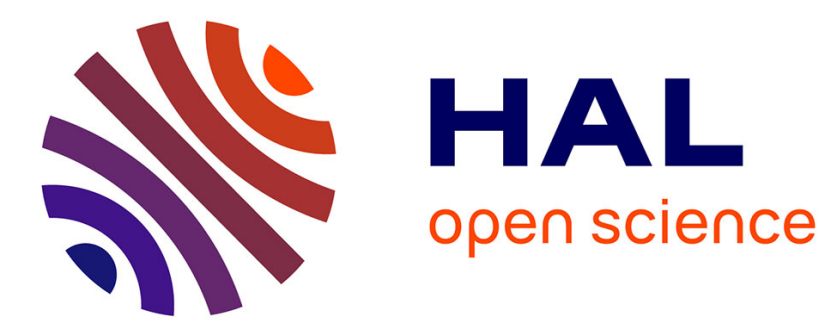

\title{
Development of a precision machine to perform and study orthogonal micro-cutting
}

\author{
Guillaume Fromentin, Jennifer Gasparoux, Kossi Agbeviade, Jacques
}

Giovanola

\section{- To cite this version:}

Guillaume Fromentin, Jennifer Gasparoux, Kossi Agbeviade, Jacques Giovanola. Development of a precision machine to perform and study orthogonal micro-cutting. Production Engineering. Research and Development, 2016, 10 (2), pp.217-226. 10.1007/s11740-016-0657-8 . hal-01327980

\section{HAL Id: hal-01327980 \\ https://hal.science/hal-01327980}

Submitted on 7 Jun 2016

HAL is a multi-disciplinary open access archive for the deposit and dissemination of scientific research documents, whether they are published or not. The documents may come from teaching and research institutions in France or abroad, or from public or private research centers.
L'archive ouverte pluridisciplinaire HAL, est destinée au dépôt et à la diffusion de documents scientifiques de niveau recherche, publiés ou non, émanant des établissements d'enseignement et de recherche français ou étrangers, des laboratoires publics ou privés. 


\title{
Development of a precision machine to perform and study orthogonal micro-cutting
}

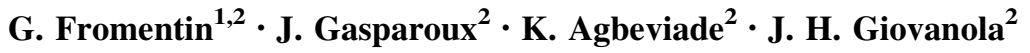

\begin{abstract}
This article presents a laboratory machine designed to perform orthogonal micro-cutting experiments. The machine allows an accurate control of the various cutting parameters and a direct comparison of micro- and macrocutting tool-material data bases. Research with the machine will focus on validating the application of macrocutting data to at least a range of microcutting applications and to define the limits beyond which such applications are no longer possible. The paper describes the machine and its design specifications and provides the validation of the performances claimed. The machine can cut in a reproducible manner with depths of cut as low as $1 \mu \mathrm{m}$, at speeds in the range $50-1000 \mathrm{~mm} / \mathrm{s}$, while measuring the cutting and thrust forces. The variability in nominal depth of cut is equal or better than $1 \mu \mathrm{m}$. Application examples illustrate the influence of lubrication and lead additions on the cutting process and demonstrate that the machine is indeed suitable for the application for which it was designed.
\end{abstract}

Keywords Orthogonal cutting - Micro cutting - Macro cutting - Precise machining - Tool-material data base . Cutting edge radius

G. Fromentin

Guillaume.fromentin@ensam.eu

1 LaBoMaP, Arts et Metiers ParisTech, Rue Porte de Paris, 71250 Cluny, France

2 Laboratoire de conception de systèmes mécaniques, Ecole Polytechnique Fédérale de Lausanne (EPFL), Lausanne, Switzerland

\section{Introduction}

This article presents a laboratory test machine designed to study orthogonal micro-cutting.

Three dimensional (3D) ultra-precision micro-machining is rapidly becoming a viable technology to fabricate small devices with features ranging in size from several micrometers to several millimeters [1]. The flexibility and efficiency of micro-cutting processes using miniature cutting tools allow for the economical fabrication of smaller batch sizes compared with other processes [2]. For instance, micro-milling allows fabrication of truly 3D surfaces that can otherwise not be produced by other competing processes, such as photolithograpy. Therefore fabricating micro-components by means of mechanical cutting processes has recently seen increasing applications and spurred renewed scientific interest in scale effects in micro-cutting [3, 4]. Reference [5] provides an extensive and up-to-date review of the field.

Commercial implementation of micro-cutting processes hinges on three closely interrelated key elements:

- the availability of efficient high precision machines adapted to micro-cutting processes,

- the availability of durable cutting tools with appropriate geometries, in particular in what concerns the cutting edge radius, and

- tool-material technological data bases for selecting the appropriate cutting parameters.

The latter element, technological data bases requires a thorough understanding of the micro-cutting processes, of the parameters controlling them and of what sets them apart from regular "macroscopic" cutting. To gain this understanding, suitable cutting tools must be available with well controlled cutting edge geometries and surface finish. 
The kinematics and dynamics of the machines used in conjunction with these tools must meet the requirements for cutting micrometer-sized chips while aiming at submicrometer work piece surface finishes. Machine dynamics must also satisfy requirements for an economical process.

Advances in actuation and control systems have enabled the development of ultra-precision machines for commercial micro-cutting (mainly turning and milling, see for instance [5-9]). Currently, the weakest element of available systems remains the spindle and the tool holding mechanism. Limitations concern rotational speed and kinematic accuracy, which are still unsatisfactory for many commercial applications.

Specific research and development has focused on developing small machines. Lu and Yoneyama [10] developed a miniaturized lathe, instrumented with a tool dynamometer and they used it to determine cutting forces in microcutting. However, the cutting speeds were low (around $1-3 \mathrm{~m} / \mathrm{min}$ for brass), limiting the range which can be experimentally studied. Ghadbeigi et al. [11] developed an orthogonal cutting device in order to analyze the material plastic deformation during orthogonal cutting, the cutting speed used was $2.4 \mathrm{~m} / \mathrm{min}$. In this study, the cutting forces were not measured. To achieve high stiffness and thermal stability, Furukawa and Moronuki [12] developed an ultra-precision machine with alumina ceramics components. To gain a more quantitative understanding of micro-cutting, Chae and Park [13] and more recently Kang et al. [14] worked on the development of ultra-precision micro-milling systems and the measurement of machining forces.

Results of research using these various systems, demonstrate that the three key size parameters influencing the micro-cutting process-and for that matter serving to define it in contrast to macro-cutting - are the radius of the cutting edge of the tool, the depth of cut and a characteristic microstructural dimension (such as average grain size, mean distance between phases or inclusions, cf. [15-17] for example). Also in general, cutting speeds attained in microcutting are significantly lower than those usually achieved in macro-cutting. The practical benefit of understanding the relationship between the two processes, micro- and macrocutting, is the possibility of extending some of the abundant tool-material databases generated at great expense for macro-cutting to micro-cutting,.

In this context and with this objective as motivation, we address in this article the development of a laboratory machine allowing the fundamental and simplified study of micro-cutting and a direct comparison with macro-cutting data. To that effect, the machine should allow precise control of the depth of cut and of the cutting speed, as well as the measurement of the relevant cutting forces. The data obtained with the machine should also serve for the development and validation of models of micro-cutting, (in particular, models taking into account not only plasticity effects but also material damage and separation processes). To meet these specifications, the machine configuration of a shaper was chosen, that affords relatively high cutting speeds (up to $60 \mathrm{~m} / \mathrm{min}$ ) compared to other microcutting research instruments.

In the remainder of the article, a general description of the machine and its performances are given. Then, the characterization of the systems is presented and the paper concludes with examples of orthogonal microcutting with the machine to illustrate its capabilities.

\section{Description of micro-orthogonal cutting machine}

Figure 1 shows photographs of the micro-orthogonal cutting machine, the specimen (work piece), a typical cutting tool, and a micro chip respectively. Figure 2 shows a schematic of the set-up, Table 1 summarizes the main specifications and performances of the machine, which will then be discussed in more details in subsequent sections.

\subsection{Description of the machine axes}

The machine operates on the same principle as a shaper and consists of two actuated and controlled axes, the $X$ - and $Z$ axes. This architecture was selected because it enables achieving near theoretical orthogonal cutting conditions (except for the effect of the free edges) and allows good manual and optical access to the tool-specimen region.

The $X$-axis supports the work piece and imposes to the table its back and forth linear motion by means of a custom designed hydrostatic guideway and of an electric linear motor. The choice of these technologies for the X-axis derived from the kinematic precision and dynamic performance-particularly acceleration and speed-specifications. The maximum bidirectional stroke (back and forth stroke) is $100 \mathrm{~mm}$, the steady state speed range is 4 to $1000 \mathrm{~mm} / \mathrm{s}$ and the maximum acceleration is limited to $2 \mathrm{~g}$, although accelerations of up to $5 \mathrm{~g}$ have been achieved. These kinematic and dynamic performances guarantee a zone of displacement at constant speed over the $20 \mathrm{~mm}$ length of the specimen for the whole achievable range of velocities (see evidence below). The hydrostatic guideway can operate with supply pressures from 4 to 10 bar.

As illustrated in Figs. 1 and 2, the specimen is carried by the table on the $X$-axis. It is held in place by a fixture integrating a piezoelectric force sensor (Kistler 9217A). Figure 3 schematically represents this arrangement. The fixture holding the specimen plays the role of a prismatic 

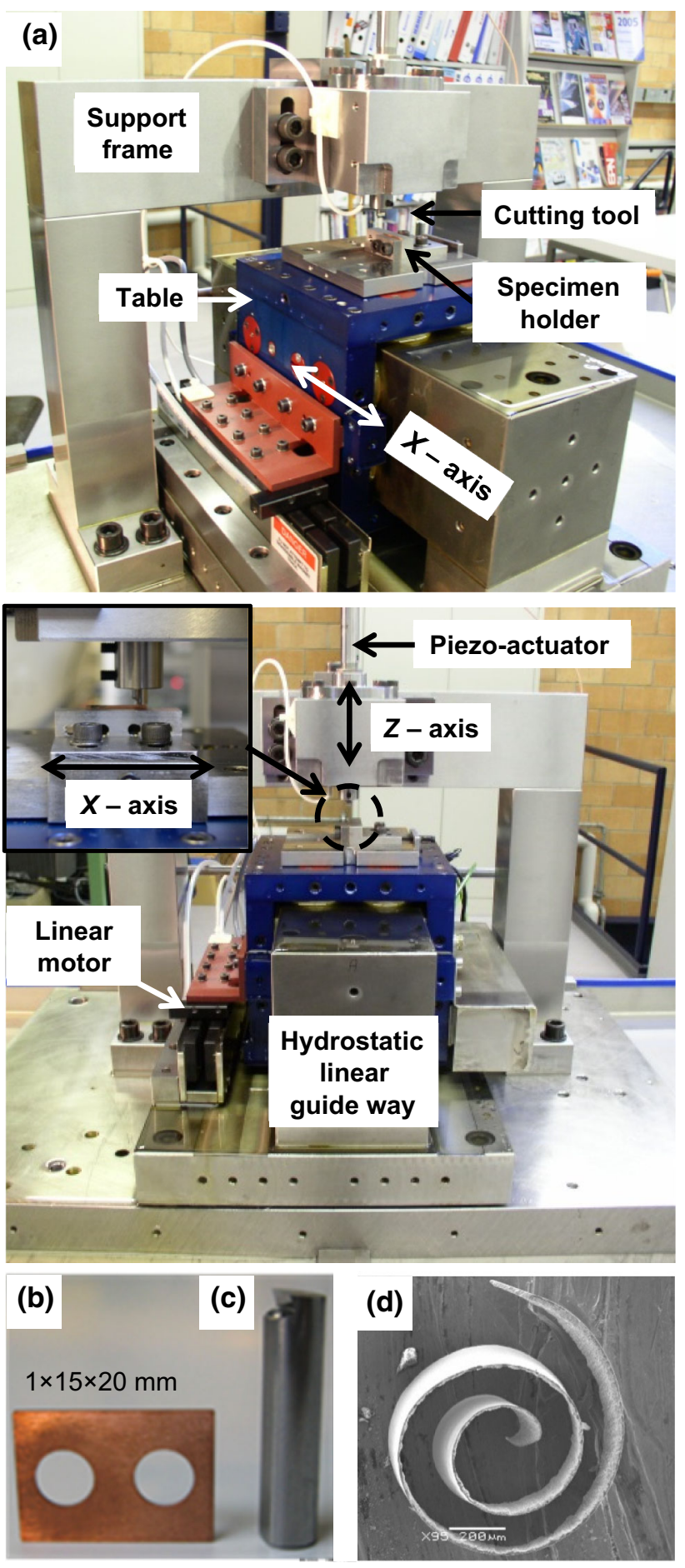

Fig. 1 a Micro-orthogonal cutting machine, b specimen, c cutting tool, $\mathbf{d}$ micro chip

joint. This configuration and the use of a piezoelectric force sensor were dictated by the imposed dynamic performances and the resulting need for a high axial stiffness.

The Z-axis, illustrated in Fig. 4, holds the tool and has both a coarse manual adjustment over a range of $25 \mathrm{~mm}$ and a fine feedback controlled positioning of 0 to $80 \mu \mathrm{m}$. The former allows adjustment of the axis after several cutting cycles have reduced the specimen height beyond the range of the latter. To perform this adjustment, the screws holding the axis support on the gantry are loosened and the axis is lowered by means of a fine pitch bolt until the tool touches the specimen surface. The four screws are then tightened again. A $\mathrm{T}$ slide in the back of the axis support imposes the kinematic accuracy of the coarse vertical displacement. Fine positioning serves to impose a preset depth of cut. The linear movement of the axis is imposed by a piezoelectric actuator, part 12 in Fig. 4 (Jena PA80/T14) and guided by a set of two thin flexible diaphragms, part 11 in Fig. 4. A solution analogous to that used for holding the specimen and transferring the cutting force to the sensor was also selected to hold the tool and transfer the thrust force to the piezoelectric sensor. These choices were dictated by the requirements for positioning accuracy for the Z-axis and the resulting need for a high axial stiffness. In summary, the Z-axis consists of two coaxial prismatic links, technologically implemented by means of two pairs of thin diaphragms and of two piezoelectric devices, one acting as force sensor and the other as a linear actuator with high positioning accuracy. An Eddy current sensor complements the axis and serves for its axial position control.

Static position calibrations of $Z$-axis (without load applied to the axis) demonstrate that the positioning accuracy is better than $0.1 \mu \mathrm{m}$. The axial stiffness of the $Z$ axis was determined by means of vibration measurements, which yielded a value of $40 \mathrm{~N} / \mu \mathrm{m}$. In a later section, it is discussed how these characteristics of the axis influence the dynamics of the cutting process and the instantaneous depth of cut and process forces.

\subsection{Instrumentation}

As summarized in Fig. 5, the orthogonal cutting machine is equipped with force and position sensors. An optical scale (Heidenhain LIP 401) measures the $X$ position of the workpiece table with micrometer resolution and provides the feedback signal for controlling the linear motor. The position of the $Z$-axis is measured by means of an Eddy current sensor (Eddy NCDT 3700), with submicrometer resolution $(6 \mathrm{~nm})$, which, as already indicated, also provides the feedback signal for controlling the axis. The worst resolution of components integrated into the $Z$-axis closed loop is $20 \mathrm{~nm}$.

As mentioned above, the specimen holder on the table of the $X$-axis includes a piezoelectric force sensor (Kistler 9217A), which measures the cutting force, whereas the $Z$ axis includes another piezoelectric force sensor, part 5 in Fig. 4 (Kistler 9215), which measures the thrust force. 


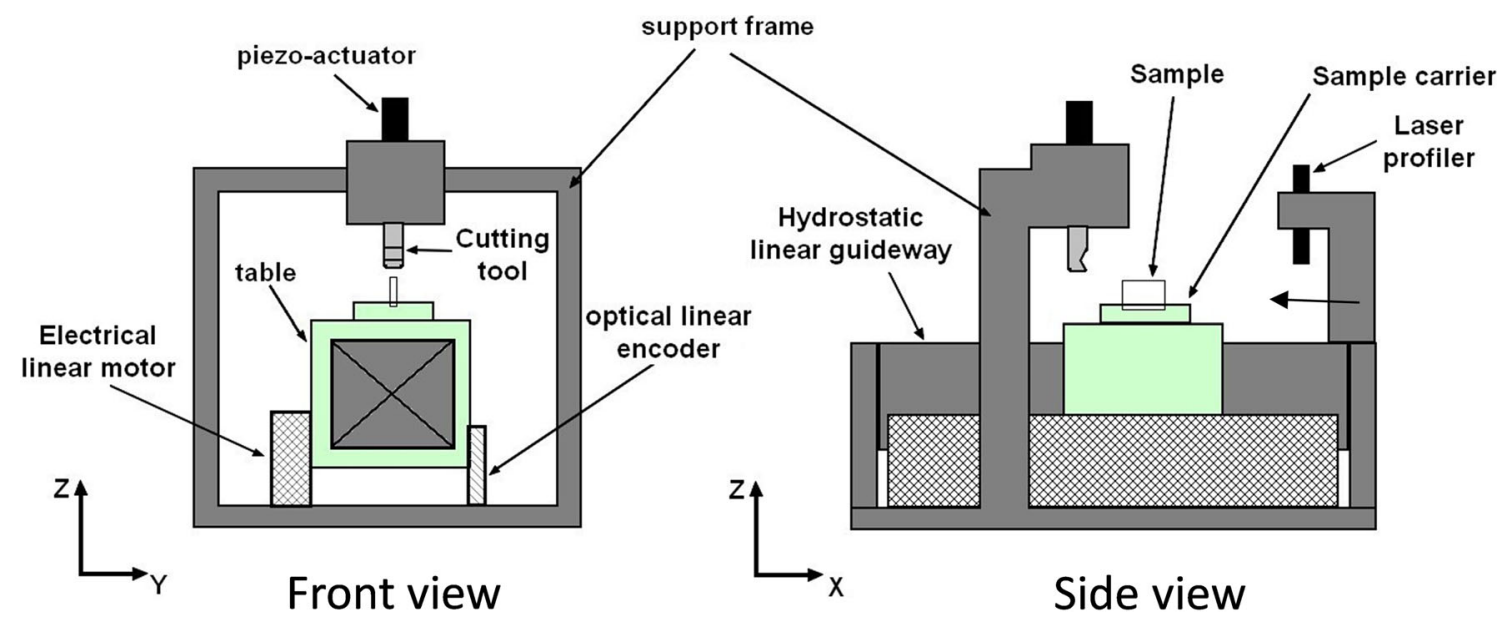

Fig. 2 Schematic of the micro-orthogonal cutting machine (for the surface measurements, the laser profiler is moved in position within the specimen displacement range)

Table 1 Main characteristics and performances of micro-orthogonal cutting machine

\begin{tabular}{ll}
\hline$X$-axis & $100 \mathrm{~mm}$ \\
Bidirectional stroke & $4-1000 \mathrm{~mm} / \mathrm{s}$ \\
Steady state speed range & $2 \mathrm{~g}$ \\
Maximum acceleration (intentionally limited) & $4-10 \mathrm{bar}$ \\
Operating pressure of guideway & $102.7 \mathrm{~N} / \mu \mathrm{m}(4 \mathrm{bar})$ \\
$Z$ and $Y$ directions stiffness & $272.5 \mathrm{~N} / \mu \mathrm{m}(10 \mathrm{bar})$ \\
& $2 \mu \mathrm{m}$ \\
Resolution of displacement encoder & $\approx 2 \mathrm{mN}$ \\
Resolution of force sensor (preload: $90 \mathrm{~N})$ & \\
$Z$-axis & $25 \mathrm{~mm}$ \\
Coarse adjustment range & $0-80 \mu \mathrm{m}$ \\
Fine positioning range & $20 \mathrm{~nm}$ \\
Resolution of the control loop & $<0.1 \mu \mathrm{m}$ \\
Positioning accuracy & $40 \mathrm{~N} / \mu \mathrm{m}$ \\
Axis Z-direction stiffness & $\approx 2 \mathrm{mN}$ \\
Sensitivity of force sensor (preload: $90 \mathrm{~N})$ & \\
Laser profiler (Z-elevation) & $\pm 0.5 \mathrm{~mm}$ \\
Range & $20 \mathrm{~nm}$ \\
Resolution &
\end{tabular}

Thus the system can measure dynamically both components of the force acting on the tool during orthogonal cutting and allows the experimental characterization of the specific energy for various test conditions.

Both $X$ - and $Z$-force sensors are mounted in the overall system by means of flexible elements acting as kinematic links and are preloaded (cf. Figs. 3, 4 for an illustration of this assembly method). As a consequence, the $X$ - and $Z$ components of the tool cutting forces do not follow a single path to their respective sensors. Rather, part of the load

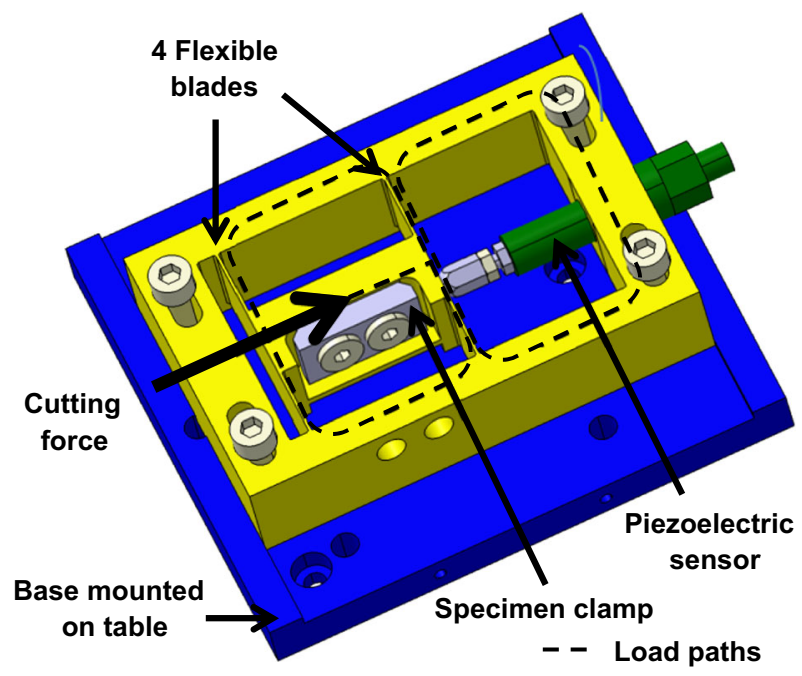

Fig. 3 Details of the specimen holder with the $X$-force measurement system

deflects the flexible elements and the other transfers to the sensor (branching in two parallel load paths). The proportion transferred to the sensor depends on the ratio of the stiffnesses of the two branches of the load path. To take this branching of the load path into account and ensure that the measurement system is linear over the whole working range, calibrations of the complete $X$ - and $Z$-force measurement systems were performed with the pre-stressed sensors mounted on the flexible links.

The static calibrations of the measured force versus applied force demonstrated that the two load measurement systems behave linearly over the design measurement range and that the load measurements are repeatable. The sensors receive about 90 and $70 \%$ of the applied load for the $X$ - and Z-loads, respectively, the remainder being 


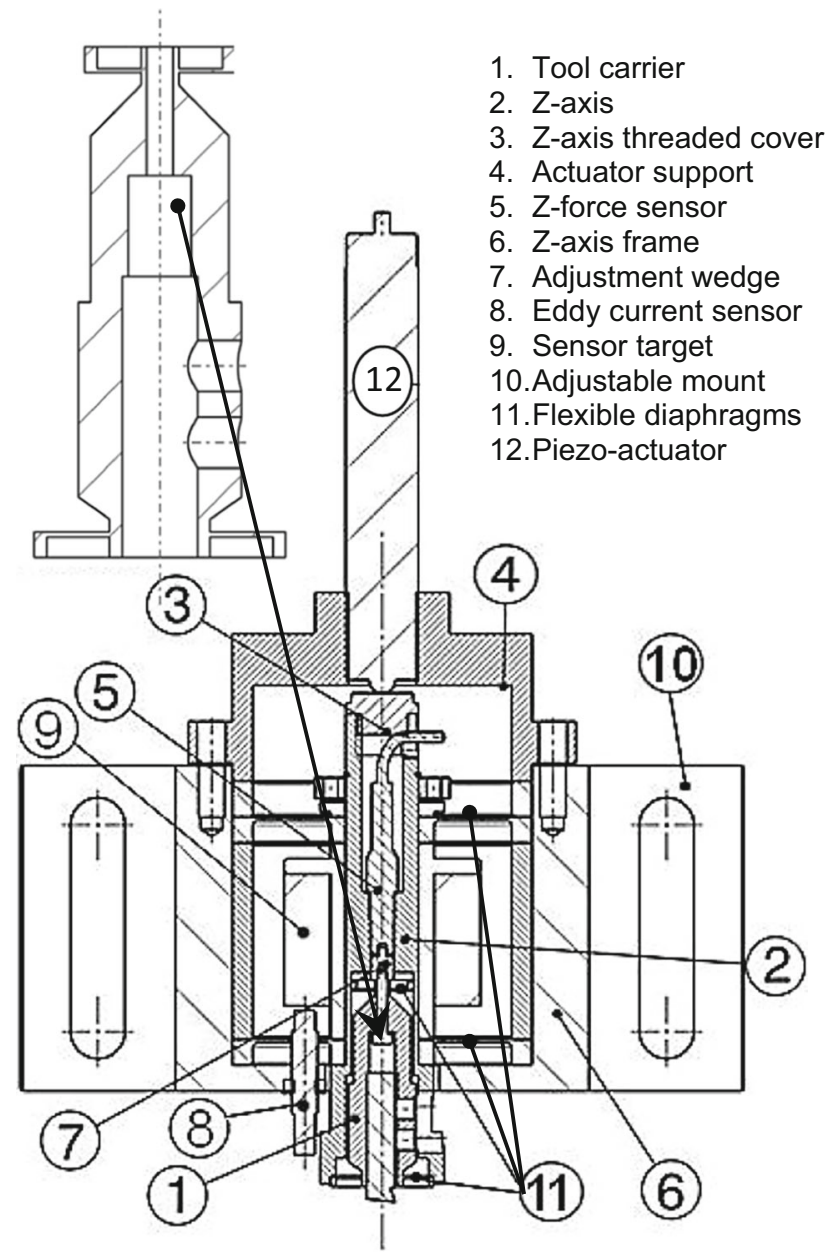

Fig. 4 Details of the $Z$-axis design with magnified sketch of tool holder (at right)

transferred to the flexible blades or the thin diaphragms. Measurements with a force applied transversely to the $Z$ axis-and thus applying parasitic bending moments to the $Z$-force measurement system - show that the errors induced by these parasitic moments are smaller than $1 \%$.

A laser profiler (Keyence LC-2400 W with LC-2430 head) complements the axes force and displacement sensors. The beam aiming normal to the machined surface of the specimen scans a line across it during table translation. The profiler is used to determine the true cut thickness. Two measurements are performed: one before cutting and one after; the difference between the two measurements provides the thickness of material removed (cf. Fig. 7 and discussion in the next section). For the measurements, the sensor is moved in position above the specimen, as indicated in Fig. 2.

Force and laser profiler measurements are acquired with a digital oscilloscope, while displacement data are acquired and stored directly on the control PC-computer. The PCcomputer also provides the time synchronization trigger signal for the oscilloscope (Fig. 5).
In summary, the developed testing system allows to measure effective depth of cut and cutting forces for various materials, while varying the tool geometry (rake angle, radius of cutting edge, tool material) and the cutting conditions (nominal uncut chip thickness and cutting speed). The configuration of the system is such that cut chips can easily be recovered from the tool holder after each pass of the tool for observation and high speed photographs of the process can be taken with a relatively simple arrangement.

\section{Characterization of the machine}

The value of the data generated with an experimental facility such as the orthogonal microcutting machine described here depends on the quality of the measurements it can perform. As summarized above, the data of interest include the cutting forces, the cutting speed and the uncut chip thickness (depth of cut).

To support and validate the design of the machine, the machine and the data acquired were characterized by analysis and simulations such as

- Simulations of transient motions of the table with a simple one dimensional non-linear viscous model,

- Numerical and analytical modal analyses, and direct measurements of:

- Speed vs position of the table,

- Motor current/force vs time,

- Yaw, tilt and roll of the table,

- Depth of cut, uncut chip thickness

- Cutting and thrust forces and tool Z-displacement during cutting,

- Eigen frequencies of the system.

Reference [18] provides a detailed account of the procedures used to characterize the dynamic behavior of the machine and the data it yields. It is demonstrated that the sensors and the systems in which they are integrated behave linearly and have sufficient resolution for the application (cf. Table 1). It is further established how the kinematics and dynamics of the complete machine affect the measurements: it is also shown that deformations and vibrations induced by the acceleration of the table and by the cutting forces either are negligible or can be accounted for in the test procedures. A summary of the key results is provided below.

\subsection{Constancy of the cutting speed}

It is demonstrated that during the back and forth motion of the table, constant speeds over the length of the cut specimen $(20 \mathrm{~mm})$ are always achieved for the range of useable cutting speeds $(0-1000 \mathrm{~mm} / \mathrm{s})$. 
Fig. 5 Schematic of the measurement and data acquisition system

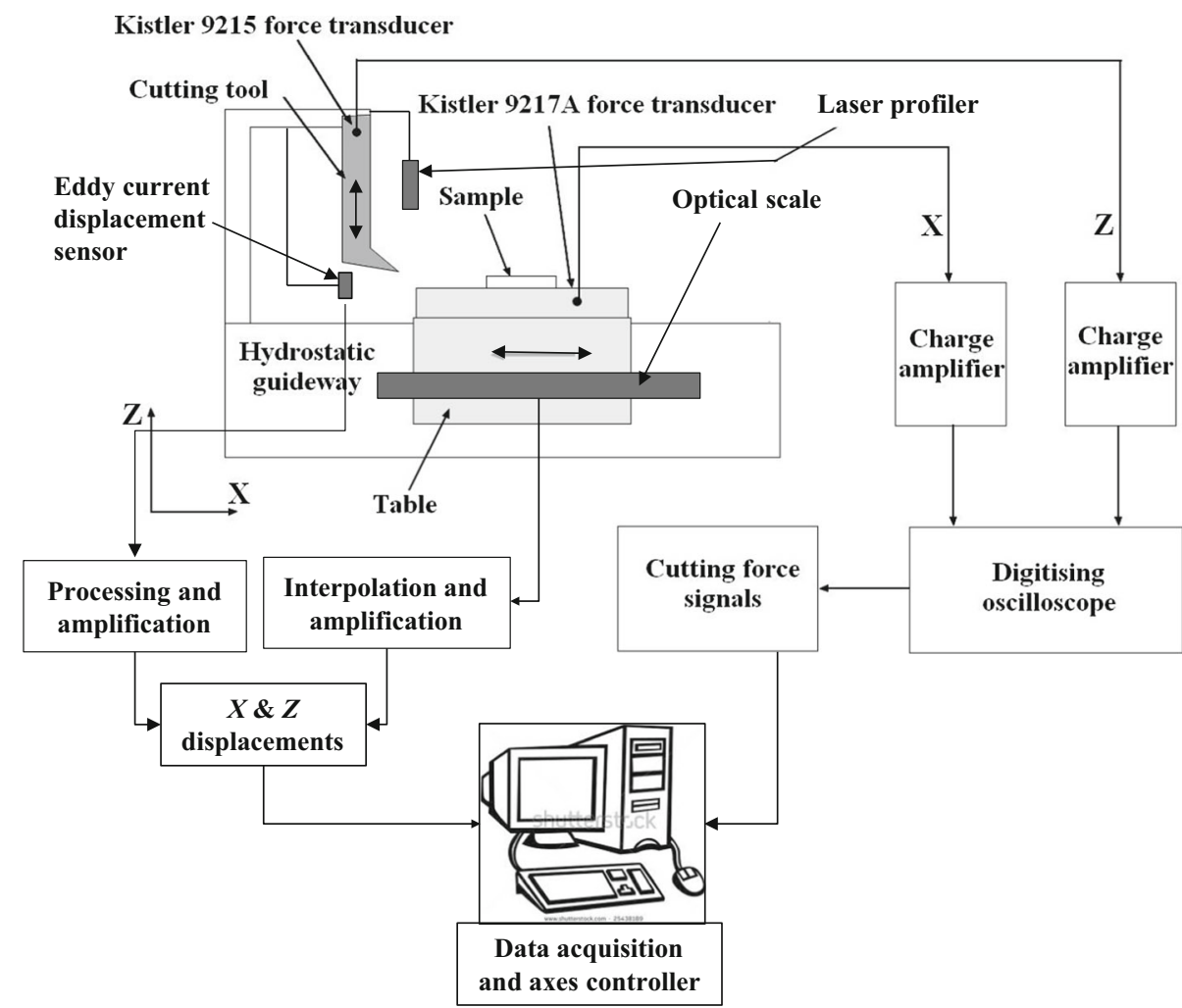

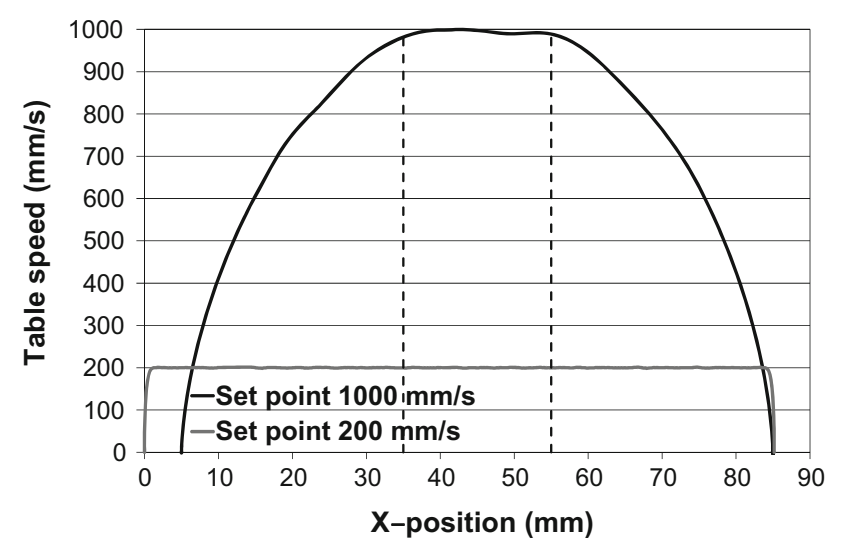

Fig. 6 Table speed as a function of $X$-position, a $1000 \mathrm{~mm} / \mathrm{s}$ and b $200 \mathrm{~mm} / \mathrm{s}$ nominal speed

Figure 6 shows measurements of the instantaneous table speed as a function of position for two programmed steady state speeds, 200 and $1000 \mathrm{~mm} / \mathrm{s}$ respectively and a supply pressure of 10 bar for the hydrostatic guideway. The measurements (performed without cutting a specimen) demonstrate that the table speed is sufficiently constant over the length of the specimen (20 mm center portion). Selected measurements during the actual cutting process further demonstrate that the speed is not significantly affected by the cutting forces, i.e. that the controller is able to maintain the table speed at its set value.

\subsection{Kinematics and dynamics of the table}

The Kinematics and dynamics of the table are affected by (1) the motor force, which is not applied through the center of mass, (2) by viscous drag of the oil on the axis guide (effect dependent on speed but independent of supply pressure) and (3) by the hydrodynamics of the hydrostatic pads during transients (dependent on oil supply pressure, independent on speed).

The tilt, yaw and roll of the moving table induced by the combination of the three effects listed above were calculated from three simultaneous translation measurements during back and forth motions using three Eddy current sensors. One first set of measurements allowed the evaluation of the tilt and roll of the table, whereas a second set, with the sensors rotated $90^{\circ}$ with respect to the X-axis provided the yaw. The results of the measurements performed for several table speeds and hydrostatic pressures demonstrated that tilt, yaw and roll have a small or negligible effect on the cut thickness and the chip geometry. Tilt has the greatest influence and at high cutting speeds can induce chip thickness variations of up to $0.7 \mu \mathrm{m}$. These rotational effects can be accounted in the experimental 
Fig. 7 Line profile of specimen topography for the initial surface (offset in the figure), the reference cut and three subsequent cuts; (copper, rake angle $0^{\circ}$, cutting speed $880 \mathrm{~mm} /$ $\mathrm{s}$, nominal depth of cut $10 \mu \mathrm{m}$ )

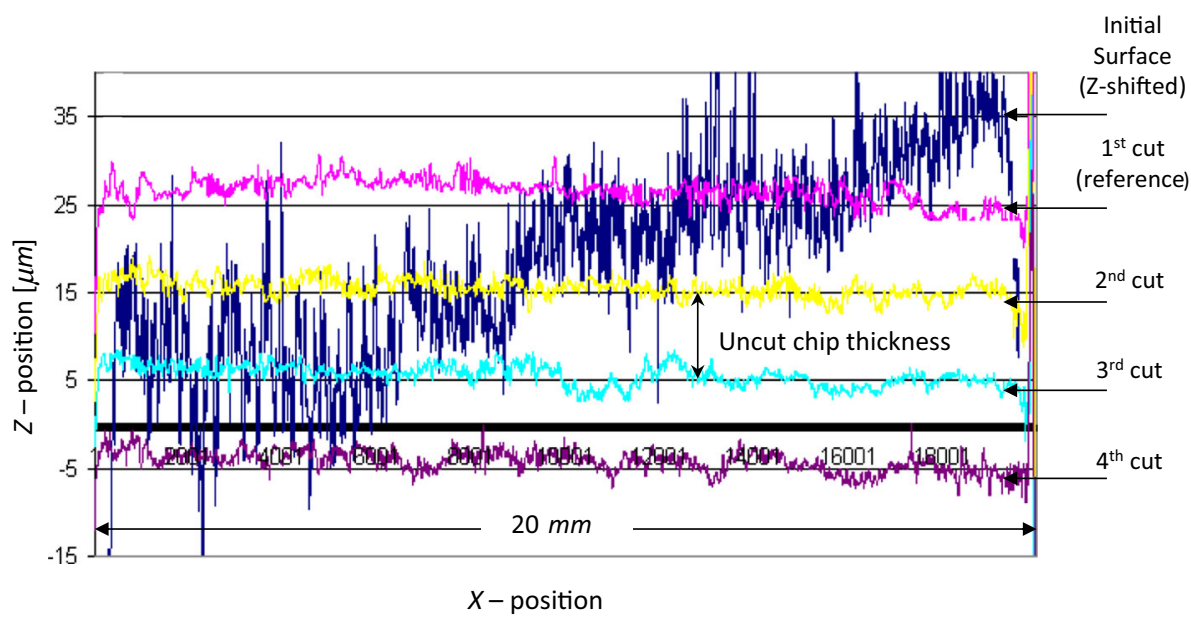

procedure and eliminated by means of an initial preconditioning cut under the same conditions as for the subsequent experiments. The preconditioning cut affords an initial reference surface that will be in first approximation parallel to the surfaces formed by subsequent cuts (cf. Fig. 7 and discussion below).

\subsection{Depth of cut/uncut chip thickness}

The depth of cut can be programmed with accuracy better than $1 \mu \mathrm{m}$ and it varies by less than $\pm 1 \mu \mathrm{m}$ during the cut. Figure 7 illustrates this result. It shows a $Z$-height profile along the $X$-direction of a copper specimen, before the preconditioning cut and after four subsequent cuts of a nominal depth of $10 \mu \mathrm{m}$. The cutting conditions are provided in the legend for the figure. In Fig. 7, the mean horizontal line fitted through each profile represents the mean specimen surface at the location of the scan, whereas the fluctuations around this mean line represent the surface roughness. The depth of cut is then the difference between two mean surface lines resulting of subsequent cuts.

Further, sets of multiple cuts each performed on the same specimen with the same tool and the same cutting conditions by incrementing the depth of cut of the nominal value, demonstrate the good reproducibility of the desired depth of cut. Results of such measurements are presented in Fig. 8 for experiments on a 316L stainless steel at a cutting speed of $100 \mathrm{~mm} / \mathrm{s}$ and a nominal depth of cut of $5 \mu \mathrm{m}$. The tool had a rake angle of $16^{\circ}$ and a cutting edge radius smaller than $5 \mu \mathrm{m}$. Two sets of cuts were performed: one with $^{1}$ and one without lubrication.

The results in Fig. 8 demonstrate that the measured average depth of cut is quite reproducible and close to

\footnotetext{
${ }^{1}$ Before the test, oil from the hydrostatic guideway was applied with a brush to the specimen surface and the cutting tool.
}

the nominal value. For lubricated and unlubricated cuts the mean measured value and the standard deviation (of the sample of mean values) are $5.03 \pm 0.22$ and $5.06 \pm 0.45 \mu \mathrm{m}$, respectively.

\subsection{Vibration characteristics of the machine}

Analytical, numerical and experimental analysis revealed the two primary vibrational modes that influence the cutting process: (1) the forward flexion mode of the gantry supporting the $Z$-axis with a frequency of $295 \mathrm{~Hz}$ and (2) the $X$ axial mode of the specimen holder (cf. Fig. 3) with a frequency of roughly $2500 \mathrm{~Hz}$. Spectral analysis demonstrated that these two frequencies clearly appear in the load records as shown is the next section. Thus they induce variations of the instantaneous process loads and of the depth of cut.

\section{Examples of orthogonal cutting experiments; cutting force measurements}

The capability of the orthogonal microcutting machine described in this study is now illustrated by presenting and discussing a few results from cutting experiments.

The first cutting experiments were conducted on $316 \mathrm{~L}$ stainless steel with a WC tool (cutting edge radius $\mathrm{r}_{\beta}<5 \mu \mathrm{m}, 16^{\circ}$ nominal rake angle). Cutting conditions were: $5 \mu \mathrm{m}$ depth of cut, and $100 \mathrm{~mm} / \mathrm{s}$ cutting speed. For these experiments, the ratio of depth of cut to cutting edge radius was close to 1 , so that the effective rake angle was negative. One set of experiments was performed without lubrication, whereas for a second set, oil was applied on the specimen before the cut. Figure 9 shows the recorded cutting and thrust forces, $F_{c}$ and $F_{t}$, respectively, for the two test conditions and the corresponding cut chips are shown in Fig. 10. 


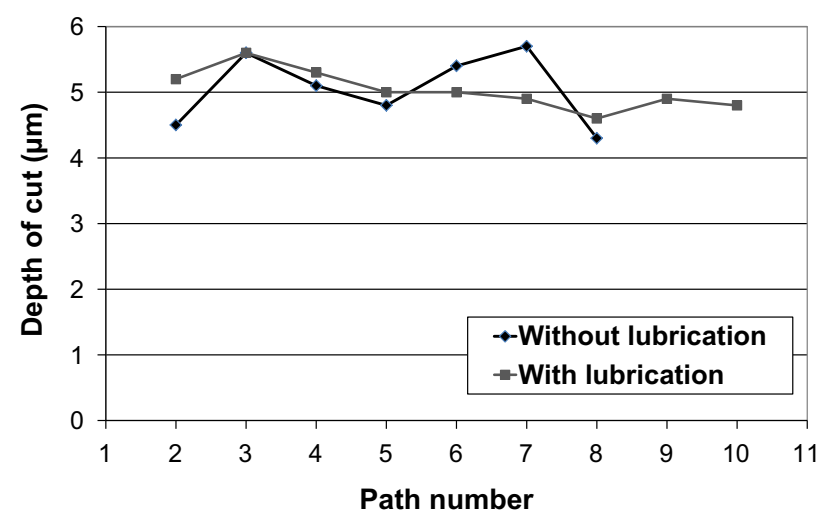

Fig. 8 Measured depth of cut as a function of path number for a set nominal depth of cut of $5 \mu \mathrm{m}$ for lubricated and unlubricated experiments on 316L stainless steel [19]
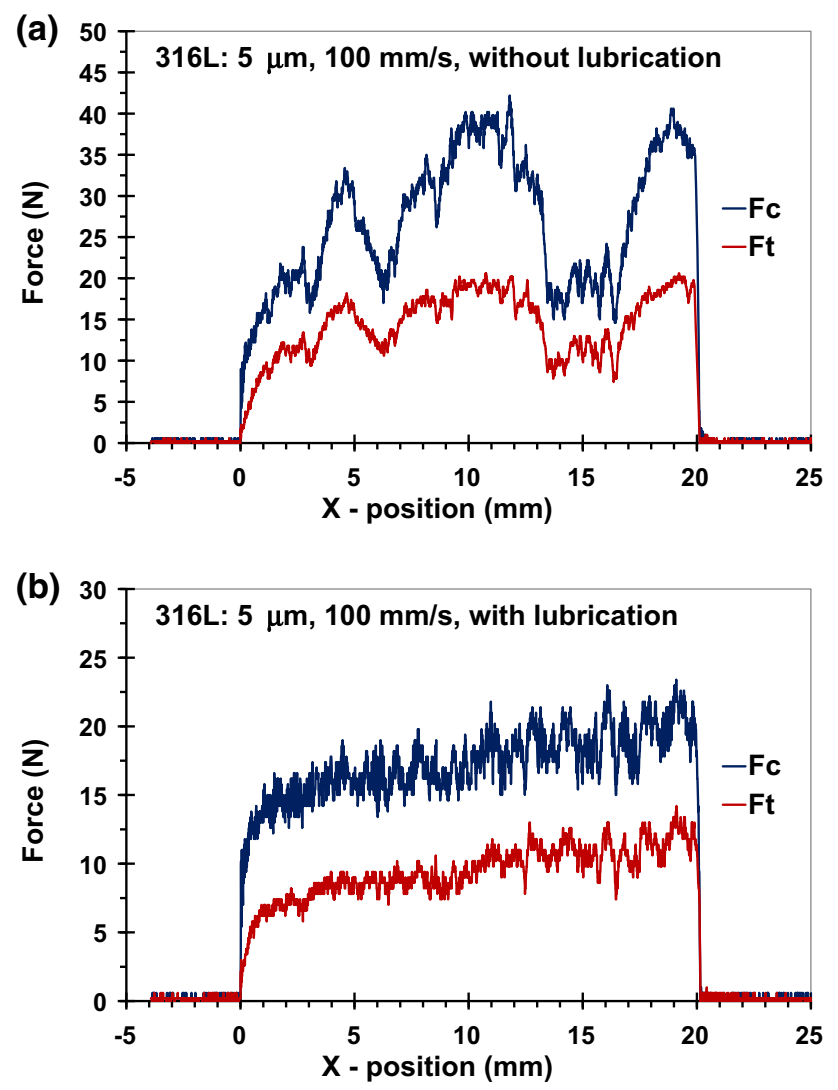

Fig. 9 Force measurements as a function of position for $316 \mathrm{~L}$ stainless steel cut. a Without and $\mathbf{b}$ with lubrication

The second set of experiments pertains to cutting a $9 \mathrm{wt} \%$ $\mathrm{Zn}$ brass with a depth of cut of $10 \mu \mathrm{m}$ and a cutting speed of either 50 or $950 \mathrm{~mm} / \mathrm{s}$. The cutting tool had a rake angle of $20^{\circ}$ and a cutting edge radius on the order of $15 \mu \mathrm{m}$. Because of the high value of this radius with respect to the depth of cut, the effective rake angle is negative. Figure 11 shows the respective cutting force records.
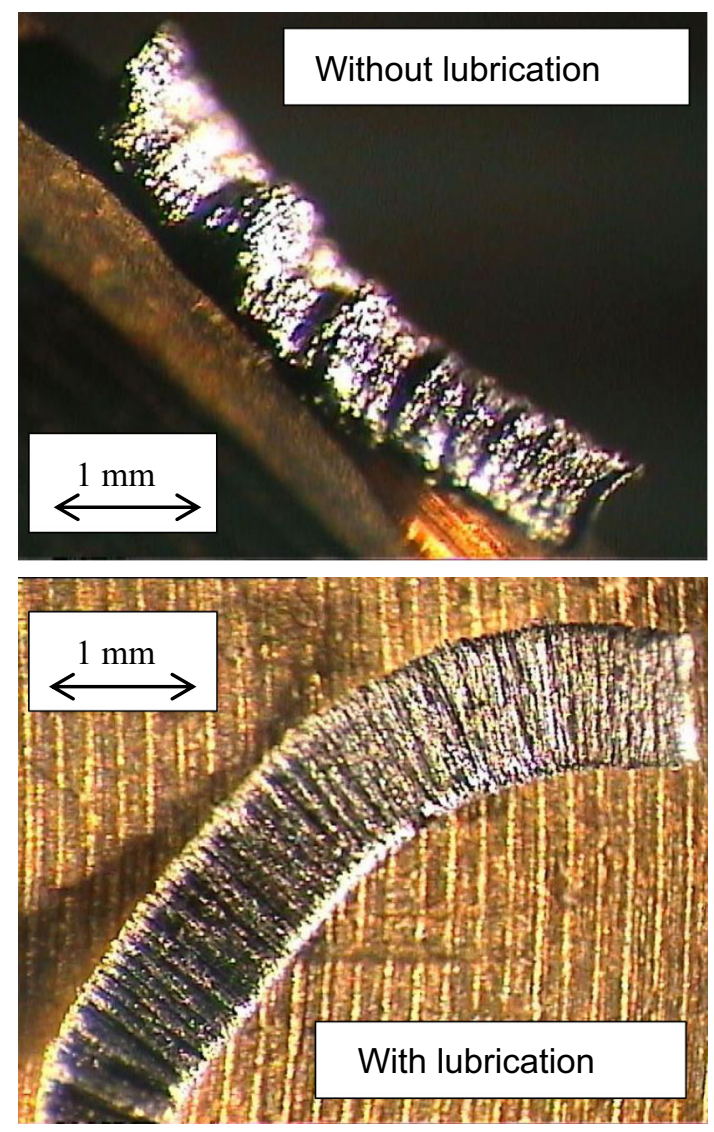

Fig. 10 Photographs of the $316 \mathrm{~L}$ chips corresponding to the force records of Fig. 9

The third set of experiments pertains to cutting essentially the same brass as the one in the second set of experiments, but this time the alloy contains $2 \mathrm{wt} \%$ of lead to improve machinability. Figure 12 shows the corresponding cutting force records for cutting speeds of 50 and $950 \mathrm{~mm} / \mathrm{s}$, respectively.

The three presented examples are discussed in terms of the machinability data obtainable with the orthogonal microcutting machine and of the information content of the force records. Multiple experiments performed under the same conditions and with the same material [19] demonstrate that the cutting data are quite reproducible (deviation from the average value smaller than $5 \%$ ).

The data in Figs. 9, 11 and 12 demonstrate that force measurements are sensitive enough to bring to light the influence of such parameters as microstructure or cutting conditions on the force measurements. Lubrication has a large influence on the cutting forces when cutting thin chips in the microcutting regime (chip thickness approaching the size of the cutting edge radius). As is wellknown from experience, lead additions to free cutting alloys drastically reduce the cutting forces and this effect is evidenced in Figs. 11 and 12 where the corresponding 

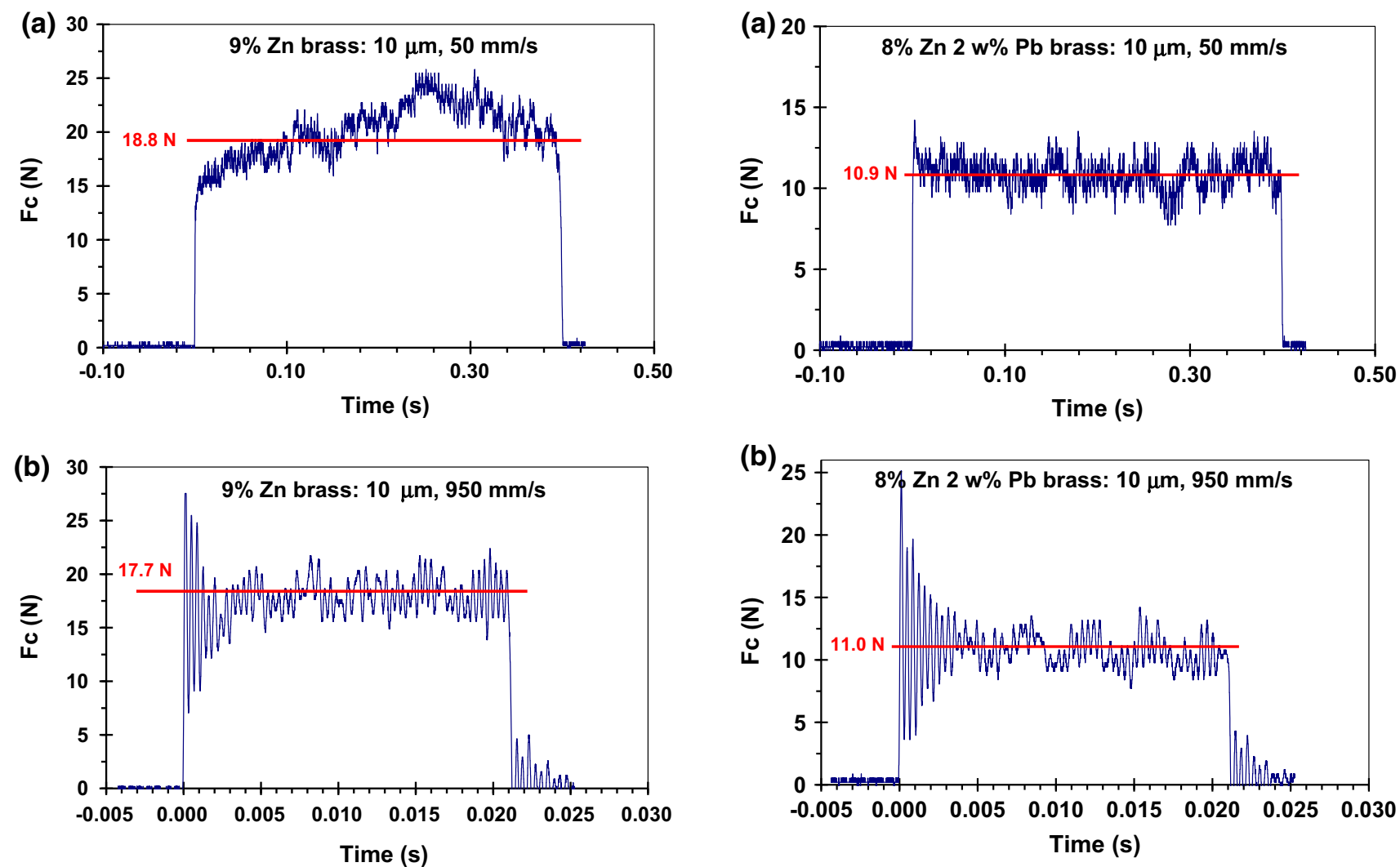

Fig. 11 Cutting force measurement for a $9 \% \mathrm{Zn}$ brass. Cutting conditions: depth of cut $10 \mu \mathrm{m}$, cutting speed $50 \mathrm{~mm} / \mathrm{s}(\mathbf{a}), 950 \mathrm{~mm} / \mathrm{s}$ (b)

cutting forces are reduced by more than $35 \%$ by the addition of lead to the $9 \mathrm{wt} \% \mathrm{Zn}$ brass. Figures 9, 11 and 12 also show significant differences in the load histories. These differences can be induced by at least three causes:

- They may reflect differences in the cutting process itself; this is the case for the course differences in the load histories for the cuts with and without lubrication (Figs. 9, 10). The large fluctuations in the cutting force observed in Fig. 9a when no lubrication is applied can be correlated with the large buckles of the corresponding chip in Fig. 10. Note also that the fluctuations in the thrust forces more or less track those in the cutting force.

- Fluctuations in the recorded forces may also be due to the influence of the machine dynamics. This is particularly the case for the variations observed at high cutting speeds (Figs. 11b, 12b). At high speeds, the first engagement of the tool in the work piece causes a shock that induces a large force spike followed by damped vibrations. A Fourier analysis of the forces reveals at least two frequencies that match eigenfrequencies of the system: one at around $280 \mathrm{~Hz}$ which corresponds to the first mode of vibration of the gantry supporting the

Fig. 12 Cutting force measurement for a $8 \% \mathrm{Zn} 2 \mathrm{wt} \% \mathrm{~Pb}$ brass. Cutting conditions: depth of cut $10 \mu \mathrm{m}$, cutting speed $50 \mathrm{~mm} / \mathrm{s}(\mathbf{a})$, $950 \mathrm{~mm} / \mathrm{s}(\mathbf{b})$

$Z$-axis and one at around $2500 \mathrm{~Hz}$ corresponding to the axial mode of vibration of the tool-holder $X$-force sensor system.

- Finally the sampling rate of the data acquisition system in combination with the cutting speed, clearly affects the force records and the ability to capture the full frequency content. This point is well illustrated in Figs. 11 and 12.

\section{Summary and conclusions}

In this article, a machine embedded force sensors, to perform orthogonal microcutting experiments is described and its performances critically assessed. It is shown that the machine allows controlling the depth of cut to within $1 \mu \mathrm{m}$ and has a force resolution amply sufficient to detect the effects of process parameters and of material microstructure on specific energy and on some of the dynamics of the process. The machine presents the attractive feature that it can achieve relatively high cutting speeds (compare to the range of investigation in micro milling study e.g.). The influence of the dynamics of the machine itself cannot be fully 
eliminated, but at least it is well characterized and remains within reasonable bounds to allow the evaluation of the microcutting process for various materials and cutting tools. At this stage the principal limitation to a fundamental study of microcutting with the new machine are the cutting tools themselves and more precisely the sharpness of their cutting edge. Up till now, tools have been used, the smallest cutting edge radius of which is $2.5 \mu \mathrm{m}$. This value is on the same order as the thickness of the smaller chips that were cut, so that the tool geometry, in particular the rake angle is no longer uniquely defined. In order to perform fundamental studies of microcutting with well-defined tool geometries and to compare the results to macrocutting data, it will be necessary to use tools with much sharper cutting edge radius. Such tools can be produced for instance by cleavage of single crystal ceramics or by ion-milling of polycrystalline ceramics (cf. Chapters 3, 7 and 8 of [5]).

The examples presented for illustration of the machine capabilities already allow interesting observations such as the strong effect of lubrication conditions on microcutting, and the associated influence of the chip formation on the cutting force. The machine has already been used in an internal project to investigate the effect of lead additions to brass and sulfured inclusions in austenitic stainless steel in micromachining. This study demonstrated the importance of damage and failure processes in the shear zone, as well as that of inclusion density on microcutting.

Acknowledgments Many more staff and students of LCSM-EPFL and LaBoMaP-Arts et Métiers ParisTech than just the authors contributed to the development of the machine described in this article. Here we would like to acknowledge the contributions of Dr. Alain Schorderet and Dr Daniel Kremer, Mrs. Olivier Loutan, Christophe Darioli, Michael Stämpfli, Egoitz Unsain, Marc Jeanneret, Quentin Theurillat, Jean-Baptiste Anne, Hubert Clément, and François Mourot. They all greatly helped us in the design, fabrication, characterization and understanding of the behavior of the orthogonal microcutting machine.

\section{References}

1. Chae J, Park SS, Freiheit T (2006) Investigation of micro-cutting operations. Int J Mach Tool Manuf 46:313-332
2. Weck M, Fischer S, Vos M (1997) Fabrication of microcomponents using ultraprecision machine tools. Nanotechnology $8: 145-148$

3. Liu K, Melkote SN (2007) Finite element analysis of the influence of tool edge radius on size effect in orthogonal micro-cutting process. Int J Mech Sci 49:650-660

4. Liu X, Devor RE, Kapoor SG, Ehmann KF (2004) The mechanics of machining at the microscale: assessment of the current state of the science. J Manuf Sci Eng Trans ASME 126:666-678

5. Cheng K, Huo D (2013) Micro-cutting: fundamentals and applications. Wiley, Hoboken, New Jersey

6. Willemin Macodel SA http://www.willemin-macodel.com/en/ products/milling-from-slug-stock/701s-3-axis-machining-centre

7. Kugler GmbH. http://www.kugler-precision.com/index. php?Mikrobearbeitungszentren

8. KERN Microtechnik GmbH. http://www.kern-microtechnic.com/ page.php?page_id=5\&lid=2

9. Fanuc Corporation. http://www.fanuc.co.jp/en/product/robonano/ index.htm

10. Lu Z, Yoneyama T (1999) Micro cutting in the micro lathe turning system. Int J Mach Tool Manuf 39:1171-1183

11. Ghadbeigi H, Bradbury SR, Pinna C, Yates JR (2008) Determination of micro-scale plastic strain caused by orthogonal cutting. Int J Mach Tool Manuf 48:228-235

12. Furukawa Y, Moronuki N (1988) Effect of material properties on ultra precise cutting processes. CIRP Ann Manuf Technol 37:113-118

13. Chae J, Park SS (2007) High frequency bandwidth measurements of micro cutting forces. Int J Mach Tool Manuf 47:1433-1441

14. Kang IS, Kim JH, Hong C, Kim JS (2010) Development and evaluation of tool dynamometer for measuring high frequency cutting forces in micro milling. Int $\mathrm{J}$ Precis Eng Manuf $11: 817-821$

15. Simoneau A, Ng E, Elbestawi MA (2006) Chip formation during microscale cutting of a medium carbon steel. Int J Mach Tool Manuf 46:467-481

16. Simoneau A, Ng E, Elbestawi MA (2007) Grain size and orientation effects when microcutting AISI 1045 steel. CIRP Ann Manuf Technol 56:57-60

17. Zhou M, Ngoi BKA, Zhong ZW, Wang XJ (2001) The effect of material microstructure on microcutting processes. Mater Manuf Process 16:815-828

18. Giovanola JH, Fromentin G, Gasparoux J, Theurillat Q, Mourot F, Agbeviade K, Kremer D (2014) Development of a micromachine to perform and study orthogonal micro-cutting. LCSMreport 2014-1, Ecole Polytechnique Fédérale de Lausanne (EPFL)

19. Lungu S, Mourot F (2010) Caractérisations de matériaux à usinabilité améliorée en micro-usinage. Master thesis, Arts et Métiers ParisTech, Cluny 